\title{
Operational examinations of agricultural tractors John Deere 6830 supplied with rape oil
}

\begin{abstract}
Subject of the study was the analysis of power parameters of three prototype of agricultural tractors John Deere model 6830, prepare to rapeseed oil as a fuel, operated since three years on different farmsteads. Energy parameters were tested of engine supplied with this oil (RO), then a control test was performed on diesel fuel (NO), according to the standard EN 590. Power of the tested tractors powered by rapeseed oil in relation to diesel fuel at $1700 \mathrm{rpm}$ was about 7-15\% lower. Total consumption of fuel for both testing fuels oil was about 24-26 kg $\cdot h^{-1}$ at 1600-1900 rpm. Based on gathered tests results, it was found that unitary consumption of fuel was higher by about $11 \%$ than in case of diesel fuel.
\end{abstract}

Key words: rape oil, bio-fuels, power parameters, agricultural tractor

\section{Badania eksploatacyjne ciągników rolniczych John Deere 6830 zasilanych olejem rzepakowym}

\begin{abstract}
Przedmiotem badań była analiza parametrów energetycznych trzech prototypowych ciagników rolniczych firmy John Deere model 6830, przystosowanych fabrycznie do zasilania wyłacznie olejem roślinnym, eksploatowanych przez 3 lata $w$ różnych gospodarstwach rolnych. Wykonano pomiar parametrów energetycznych silnika zasilanego olejem rzepakowym (OR), następnie wykonano pomiar kontrolny na oleju napędowym (ON), zgodnym z norma jakości EN 590. Moc badanych ciagników zasilanych olejem rzepakowym, względem mocy uzyskanej na oleju napędowym, przy 1700 min $^{-1}$ była niższa 7-15\%. Godzinowe zużycie oleju rzepakowego w odniesieniu do oleju napędowego wynosito średnio 24-26 kg $h^{-1}$ przy 1600-1900 $\mathrm{min}^{-1}$. Na podstawie zebranych wyników badań stwierdzono, że jednostkowe zużycie paliwa byto o okoto $11 \%$ większe niż przy stosowaniu oleju napędowego.
\end{abstract}

Słowa klucze: olej rzepakowy, biopaliwa, parametry energetyczne, ciagnik rolniczy

\section{Introduction}

Diesel engines are the main source of driving power among other things in transport, construction and agriculture. Limited quantity of petroleum and high rate of its winning necessitates the search for alternative fuels to supply them, that would originate from renewable sources of energy. In Europe, one of the most extensive solutions is the production of methyl esters from rape oil. This type of fuel can be obtained based on different oils and fats [1,2]. Moreover, as a result of many scientific and research works, it was proven that used cooking oil, animal fats subjected to esterification processes or transesterification are also a valuable source of fuels [3-6].

Developed technology for bio-fuels production within the farmsteads by Frąckowiak at al. [7], allows producing bio-fuel for own needs by agricultural manufacturers. Cold technology, in which the transesterification reaction takes place at temperature $20-70{ }^{\circ} \mathrm{C}$, was described in detail by Grzybek [8]. Disadvantage of this solutions is application of highly toxic methanol as well as strongly concentrated potassium and sodium bases. As a result of the production, except the methyl esters, glycerine phase [9] is produced, a substance that is difficult to use and utilize within a farmstead $[10,11]$. Fuels from waste fats obtained using this technology are contaminated with glycerine particles and non-reacted triacylglycerols and can lead to engine failure [12].

Both, plant oils and methyl esters produced from them, can be characterized by similar calorific value. The difference

\section{Wstęp}

Silniki z zapłonem samoczynnym (ZS) są głównym źródłem napędu m.in. w transporcie, budownictwie i rolnictwie. Ograniczona ilość ropy naftowej oraz wysoki poziom jej wydobycia skutkują poszukiwaniem alternatywnych, które pochodzić będą z odnawialnych źródeł energii. W Europie jednym z przyjętych, na skalę przemysłową, rozwiązań jest produkcja estrów metylowych z oleju rzepakowego. Tego rodzaju paliwa można otrzymywać z różnych olejów i tłuszczów $[1,2]$. Ponadto w wyniku wielu prac naukowobadawczych dowiedziono, że oleje posmażalnicze, thuszcze zwierzęce poddane procesom estryfikacji lub transestryfikacji są również cennym źródłem paliw [3-6].

Opracowana przez Frąckowiaka wraz z zespołem [7] technologia produkcji biopaliw w obrębie gospodarstw rolnych umożliwia wytwarzanie przez producentów rolnych biopaliw na własne potrzeby. Technologia zimna, w której reakcja transestryfikacji zachodzi w temperaturze $20-70{ }^{\circ} \mathrm{C}$, dokładnie została opisana przez A. Grzybek [8]. Wadą tego rozwiązania jest stosowanie silnie trującego metanolu oraz silnie stężonych zasad potasowych lub sodowych. $\mathrm{W}$ wyniku produkcji oprócz estrów metylowych powstaje faza glicerynowa [9], substancja trudna do zagospodarowania i utylizacji w obrębie gospodarstwa rolnego $[10,11]$. Paliwa z tłuszczów odpadowych otrzymywane tą technologią są zanieczyszczone cząstkami gliceryny i nieprzereagowanymi triacyloglicerolami, i mogą być przyczyną awarii silnika [12]. 
is in viscosity, especially at lower temperatures [13]. To high viscosity of plant oil affects the carbon fouling in the engine combustion chamber leading to engine defect. Hemmerlein at al. has found that the rate of carbon fouling generation depend on the engine design. Engines with intermediate combustion chamber operated significantly longer than engines with direct injection, due to injector clogging [14].

There are many research works around the world that concern diesel engines supplied with different plant oils, even with heated animal fats [15]. Based on the basic research performed in laboratories, it was found that application of plant oils due to their chemical constitution affects the unitary growth of fuel consumption. During combustion of this type of fuel, dynamics of heat generation at the stage of diffusion combustion is lower comparing to the dynamics taking place during diesel fuel combustion, resulting in lower torque of the engine $[16,17,18]$.

As proved by Rathbauer at al. [19] and Pasyniuk with Golimowski [20] there are solutions that allow supplying agricultural tractors with plant oils. Based on their operational tests concerning agricultural tractors, it was found that single-tanks and double-tank fuel supply systems are, in most cases, the solution that enable using rape oil in pure form as a fuel.

The goal of the work was the impact assessment of operational period of John Deere 6830 agricultural tractors on their power parameters.

\section{Materials and methods}

The subject of research was determination of rape oil impact on energetic parameters of prototype John Deere 6830 agricultural tractors that were working 3 years on difference agricultural farm in Poland. Whole period of study tractors were working of hours on rape oil: tractor No $1-$ 1410 motor-hour, tractor No 2 - 1269 motor-hour, tractor No 3 - 1331 motor-hour. Measurement has been performed on farmsteads where the tractors were operating. Test stand consisted of John Deere 6830 agricultural tractor connected to engine brake PT $301 \mathrm{MES}$ using power take-off shaft (PTO) and fuel gauge AMX 212F installed in place of the main tractor tank.

The examined tractors were supplied with six-cylinder, twenty four-valve diesel engine model 6068HL481. Injection system: direct injection Common Rail. Engine displacement $6790 \mathrm{ccm}$, maximum power according to manufacturer $103 \mathrm{~kW}$, torque $620 \mathrm{~N} \cdot \mathrm{m}$ at $1400 \mathrm{rpm}$. Range of engine speed 1300-2100 rpm.

Mobile engine brake used during the tests, so called dynamometer PT 301 MES, consists of two air cooled electromagnetic brakes (retarders). Losses during cooling and due to friction in bearing are considered during the measurement by the control program. Engine braking takes place using retarder consisting of two rotors. As a result of driving the rotor, magnetic field generated eddy current, that counteract the rotational motion of the rotors. This counter force, via rotor, influences the drive shaft leading to braking of the tested device.
Zarówno oleje roślinne, jak i estry metylowe z nich powstałe charakteryzują się zbliżoną wartością opałową. Istotną różnicę stanowi lepkość, szczególnie w niższych temperaturach [13]. Zbyt wysoka lepkość oleju roślinnego wpływa na postawanie nagaru w komorze spalania silnika, co prowadzi do awarii silnika. Hemmerlein wraz zespołem zauważyli równie, że dynamika nawarstwiania się nagarów zależy od konstrukcji silnika. Silniki z pośrednią komorą spalania pracowały znacznie dużej niż silniki z wtryskiem bezpośrednim, z powodu zapychania się szczelin wtryskiwacza [14].

Na całym świecie prowadzi się badania nad zasilaniem silników ZS różnymi olejami roślinnym, a nawet podgrzanymi tłuszczami zwierzęcymi [15]. Na podstawie badań prowadzonych w laboratoriach stwierdzono, że stosowanie olejów roślinnych, z uwagi ich budowę chemiczną, wpływa na wzrost jednostkowego zużycia paliwa. Podczas spalania tego rodzaju paliw dynamika wydzielania ciepła w fazie spalania dyfuzyjnego jest niższa niż dynamika spalania oleju napędowego, co w efekcie wpływa na niższy moment obrotowy silnika [16, 17, 18].

Jak dowiedli Rathbauer z zespołem [19] oraz Pasyniuk z Golimowskim [20], istnieją rozwiązania pozwalające zasilać ciągniki rolnicze olejami roślinnymi. Na podstawie przeprowadzonych przez nich badań eksploatacyjnych ciągników rolniczych stwierdzono, że jednozbiornikowe i dwuzbiornikowe systemy zasilania paliwem, w większości badanych przypadków, są rozwiązaniem umożliwiającym stosowanie oleju rzepakowego w czystej postaci jako paliwa.

Celem niniejszej pracy jest ocena wpływu okresu eksploatacji ciągników rolniczych John Deere 6830 na ich parametry energetyczne.

\section{Metodyka badań}

Przedmiotem badań było określenie wpływu oleju rzepakowego na parametry energetyczne prototypowych cięgników rolniczych John Deere 6830, eksploatowanych przez 3 lata w różnych gospodarstwach rolnych. Podczas całego okresu badań ilość przepracowanych godzin była zbliżona i wynosiła odpowiednio: ciągnik nr $1-1410$ mth, ciągnik nr 2-1269 mth, ciągnik nr 3-1331 mth. Pomiar prowadzono w gospodarstwach, w których ciągniki były eksploatowane. Stanowisko badawcze składało się z ciągnika rolniczego John Deere 6830, podłączonego do hamulca silnikowego PT 301 MES przez wałek odbioru mocy (WOM) i paliwomierza AMX 212F zainstalowanego w miejscu głównego zbiornika ciągnika.

Badane ciągniki były napędzane 6-cylindrowym, 24-zaworowym silnikiem ZS model 6068HL481 o wtrysku bezpośrednim typu common rail. Pojemność silnika $6790 \mathrm{~cm}^{3}$, maksymalna moc wg producenta $-103 \mathrm{~kW}$, moment obrotowy $-620 \mathrm{~N} \cdot \mathrm{m}$ uzyskiwany przy $1400 \mathrm{~min}^{-1}$. Zakres prędkości roboczych silnika - 1300-2100 $\mathrm{min}^{-1}$.

Użyty w badaniach mobilny hamulec silnikowy, inaczej dynamometr PT 301 MES, składa się z dwóch hamulców elektromagnetycznych (retardery) chłodzonych powietrzem. Straty wynikające przy chłodzeniu i tarciu w łożyskach są uwzględnione przy dokonywanym pomiarze 
Fuel gauge as the second measurement device on the test stand, consisted of extensiometer scales, gauge of volume $1 \mathrm{dm}^{3}$ and solenoid valve, that is to control the fuel supply to the scales. The whole assembly was controlled by a programmed control system AMX $212 \mathrm{~F}$ with display showing momentary fuel consumption in $\mathrm{kg} \cdot \mathrm{h}^{-1}$.

Engine energetic parameters measurement took place according to assumed and described procedure. Before the test, cooler system of engine was warmed up to working temperature $85^{\circ} \mathrm{C} \pm 2{ }^{\circ} \mathrm{C}$. Manual acceleration lever was set to extreme position, where the engine obtained maximum revolutions, ca. $2250 \mathrm{rpm}$. Using the engine brake, the engine load was increased until obtaining revolutions according to the adopted methodology. Torque and fuel consumption values were recorder every $100 \mathrm{rpm} \pm 5 \mathrm{rpm}$ from $2200 \mathrm{rpm}$ to $1200 \mathrm{rpm}$, determining the characteristics within the full engine operation range. Additional measurement point was introduced at $1750 \mathrm{rpm}$ in order to concentrate them near the maximum power. Measurement for each type of fuel was performed three times.

At first, the tractors were supplied with plant oil, with the one that was used from the very beginning of operational examinations, and then with diesel fuel. During the examinations, summer type of diesel fuel was used of standardized parameters (EN 590), calorific value $45.4 \mathrm{MJ} \cdot \mathrm{kg}^{-1}$ and cold pressed rape oil $(\mathrm{RO})$ of below presented parameters.

Measured parameters: torque $\left(\mathrm{M}_{\mathrm{o}}\right)$ and overall fuel consumption $(\mathrm{G})$. Based on the obtained values, the following was determined: engine power $(\mathrm{Ne})$, unitary fuel consumption $\left(\mathrm{g}_{\mathrm{e}}\right)$. przez program sterujący. Hamowanie silnika odbywa się za pomocą retardera składającego się z dwóch rotorów. $\mathrm{W}$ wyniku napędzania wirnika pole magnetyczne wywołuje prądy wirowe, które przeciwdziałają ruchowi obrotowemu wirników. Ta przeciwsiła oddziałuje przez rotor na wał napędowy, dzięki czemu uzyskuje się efekt hamowania w badanym urządzeniu.

Paliwomierz, będący drugim urządzeniem pomiarowym na stanowisku badawczym, składał się z wagi tensometrycznej, miernicy o objętości $1 \mathrm{dm}^{3}$ oraz zaworu elektromagnetycznego, którego funkcją jest sterowanie dopływem paliwa do wagi. Całością sterował zaprogramowany układ pomiarowy AMX 212F z wyświetlaczem przedstawiającym chwilowe zużycie paliwa $\mathrm{wg} \cdot \mathrm{h}^{-1}$.

Pomiar parametrów energetycznych silnika odbywał się zgodnie z przyjętą i opisaną w metodyce procedurą. Przed przystąpieniem do badań ciecz chłodząca silnika rozgrzano do temperatury pracy $85^{\circ} \mathrm{C} \pm 2{ }^{\circ} \mathrm{C}$. Dźwignię gazu ręcznego ustawiono w skrajnym położeniu, gdzie silnik osiągał maksymalne obroty ok. $2250 \mathrm{~min}^{-1}$. Przy użyciu hamulca silnikowego zwiększano obciążenie silnika do chwili uzyskania prędkości obrotowej zgodnie z przyjętą metodyką. Rejestrowano wartości momentu obrotowego i zużycia paliwa co $100 \mathrm{~min}^{-1} \pm 5 \mathrm{~min}^{-1}$ od $2200 \mathrm{~min}^{-1}$ do $1200 \mathrm{~min}^{-1}$, wyznaczając charakterystykę w pełnym zakresie pracy silnika. Wprowadzono dodatkowy punkt pomiarowy przy $1750 \mathrm{~min}^{-1} \mathrm{w}$ celu zagęszczenia ich w okolicy występowania ekstremum mocy. Pomiar dla każdego rodzaju paliwa powtórzono trzykrotnie.

Ciągniki w pierwszej kolejności zasilono olejem roślinnym, tym którym zasilano je od początku badań eksploata-

Table 1. Results of rape oil parameters analysis

Tabela 1. Wyniki analizy parametrycznej oleju rzepakowego

\begin{tabular}{|c|c|c|c|c|}
\hline Parameter/parametr & Method/metoda & Result/wynik & $\begin{array}{c}\text { Specification/ } \\
\text { wymagania normy } \\
\text { DIN V } 51605\end{array}$ & $\begin{array}{l}\text { Unit/ } \\
\text { jednostka }\end{array}$ \\
\hline Density/gęstość $\left(15^{\circ} \mathrm{C}\right)$ & DIN EN ISO 12185 & 920.2 & $900-930$ & $\mathrm{~kg} / \mathrm{m}^{3}$ \\
\hline Flash point/temperatura zapłonu & DIN EN ISO 2719 & 262,5 & $\min 22 \mathrm{C}$ & ${ }^{\circ} \mathrm{C}$ \\
\hline Kin. viscosity/lepkość kinematyczna $\left(40^{\circ} \mathrm{C}\right)$ & DIN EN ISO 3104 & 34.44 & $\max 36.0$ & $\mathrm{~mm}^{2} / \mathrm{s}$ \\
\hline Calorific value/wartość opalowa & DIN $51900-2$ & 37320 & $\min 36000$ & $\mathrm{~kJ} / \mathrm{kg}$ \\
\hline Cetane number/liczba cetanowa & IP 498 & 46.2 & $\min 39$ & - \\
\hline Carbon residue/pozostałość po koksowaniu & DIN EN ISO 10370 & 0.34 & $\max 0.40$ & $\%(\mathrm{~m} / \mathrm{m})$ \\
\hline Iodine value/liczba jodowa & DIN EN 14111 & 112 & $95-125$ & $\mathrm{~g}$ Iodine $/ 100 \mathrm{~g}$ \\
\hline Sulfur content/zawartość siarki & DIN EN ISO 20884 & 5.9 & $\max 10$ & $\mathrm{mg} / \mathrm{kg}$ \\
\hline Acid value/liczba kwasowa & DIN EN 14104 & 0.890 & $\max 2,0$ & $\mathrm{mg} \mathrm{KO} \mathrm{H/g}$ \\
\hline Oxidation stability/stabilność termooksydacyjna $\left(110^{\circ} \mathrm{C}\right)$ & DIN EN 14112 & 6.7 & $\min .6 .0$ & $\mathrm{~h}$ \\
\hline Phosphorous content/zawartość fosforu & DIN EN 14107 & $<0.5$ & $\max 12$ & $\mathrm{mg} / \mathrm{kg}$ \\
\hline $\begin{array}{l}\text { Earth alkali content/zawartość metali ziem alkalicznuch } \\
(\mathrm{Ca}+\mathrm{Mg})\end{array}$ & DIN EN 14538 & $<0.5$ & $\max 20$ & $\mathrm{mg} / \mathrm{kg}$ \\
\hline Ash content/zawartość popiołu & DIN EN ISO 6245 & 0.004 & $\max 0.01$ & $\%(\mathrm{~m} / \mathrm{m})$ \\
\hline Water content/zawartość wody & DIN EN ISO 12937 & 600 & $\max 750$ & $\mathrm{mg} / \mathrm{kg}$ \\
\hline
\end{tabular}


Table 2. Tests results

Tabela 2. Wyniki badań

\begin{tabular}{|c|c|c|c|c|}
\hline Parameter/parametr & $\begin{array}{c}\text { Unit/ } \\
\text { jednostka }\end{array}$ & $\begin{array}{l}\text { Tractor No 1/ } \\
\text { ciagnik } n r 1\end{array}$ & $\begin{array}{l}\text { Tractor No 2/ } \\
\text { ciagnik } n r 2\end{array}$ & $\begin{array}{l}\text { Tractor No 3/ } \\
\text { ciagnik } n r 3\end{array}$ \\
\hline Operation time/czas pracy & mth & 1410 & 1269 & 1331 \\
\hline Consumed fuel in total/całkowite zużycie paliwa & $\mathrm{dm}^{3}$ & 16235 & 14720 & 15439 \\
\hline Maximum torque/maks. moment obrotowy $R O$ & $\mathrm{~N} \cdot \mathrm{m}$ & 507 & 510 & 544 \\
\hline Maximum torque diesel fuel/maks. moment obrotowy $O N$ & $\mathrm{~N} \cdot \mathrm{m}$ & 589 & 590 & 591 \\
\hline $\begin{array}{l}\text { Max. fuel consumption/maks. godzinowe zużycie paliwa } \\
R O\end{array}$ & $\mathrm{~kg} \cdot \mathrm{h}^{-1}$ & 24.1 & 24.2 & 25.9 \\
\hline $\begin{array}{l}\text { Max. fuel consumption diesel fuel/maks. godzinowe } \\
\text { zużycie paliwa ON }\end{array}$ & $\mathrm{kg} \cdot \mathrm{h}^{-1}$ & 24.6 & 24.3 & 25.8 \\
\hline Power at $1700 \mathrm{rpm} \mathrm{RO} / \mathrm{moc}$ przy $1700 \mathrm{~min}^{-1} \mathrm{OR}$ & $\mathrm{kW}$ & 85.6 & 87.2 & 91.7 \\
\hline Power at $1700 \mathrm{rpm}$ diesel fuel $/ \mathrm{moc}$ przy $1700 \mathrm{~min}^{-1} \mathrm{ON}$ & $\mathrm{kW}$ & 99.2 & 101.1 & 98.3 \\
\hline $\begin{array}{l}\text { Specific fuel consumption at } 1700 \mathrm{rpm} \mathrm{RO} / j e d n . \text { zużycie } \\
\text { paliwa przy } 1700 \mathrm{~min}^{-1} \mathrm{OR}\end{array}$ & $\mathrm{g} \cdot \mathrm{kWh}^{-1}$ & 282 & 278 & 277 \\
\hline $\begin{array}{l}\text { Specific fuel consumption ON at } 1700 \mathrm{rpm} \text { diesel fuel/ } \\
\text { jedn. zużycie paliwa przy } 1700 \mathrm{~min}^{-1} \mathrm{ON}\end{array}$ & $\mathrm{g} \cdot \mathrm{kWh}^{-1}$ & 248 & 240 & 261 \\
\hline
\end{tabular}

\section{Tests results}

During the operational tests, no negative impact of rape oil on the tractors mortality was observed. The below table presents the values of measured and calculated parameters of examined tractors.

Within the test period, the tractors operated for 1374 to 1774 motor-hours, consuming from $10235 \mathrm{dm}^{3}$ to $24218 \mathrm{dm}^{3}$. Power parameters of tractors 1 and 2 were comparable: $\mathrm{M}_{0}$ ca. $510 \mathrm{~N} \cdot \mathrm{m}$ supplied with RO and 590 supplied with diesel fuel. $\mathrm{M}_{\mathrm{o}}$ of tractor No 3, it power was higher comparing to the remaining objects and amounted $544 \mathrm{~N} \cdot \mathrm{m}$ using RO and 591 on diesel fuel and power $91.7 \mathrm{~kW}$ and $98.3 \mathrm{~kW}$ adequately. Similar phenomenon was noticed while the measurement of total fuel consumption, tractors 1 and 2 at rated engine

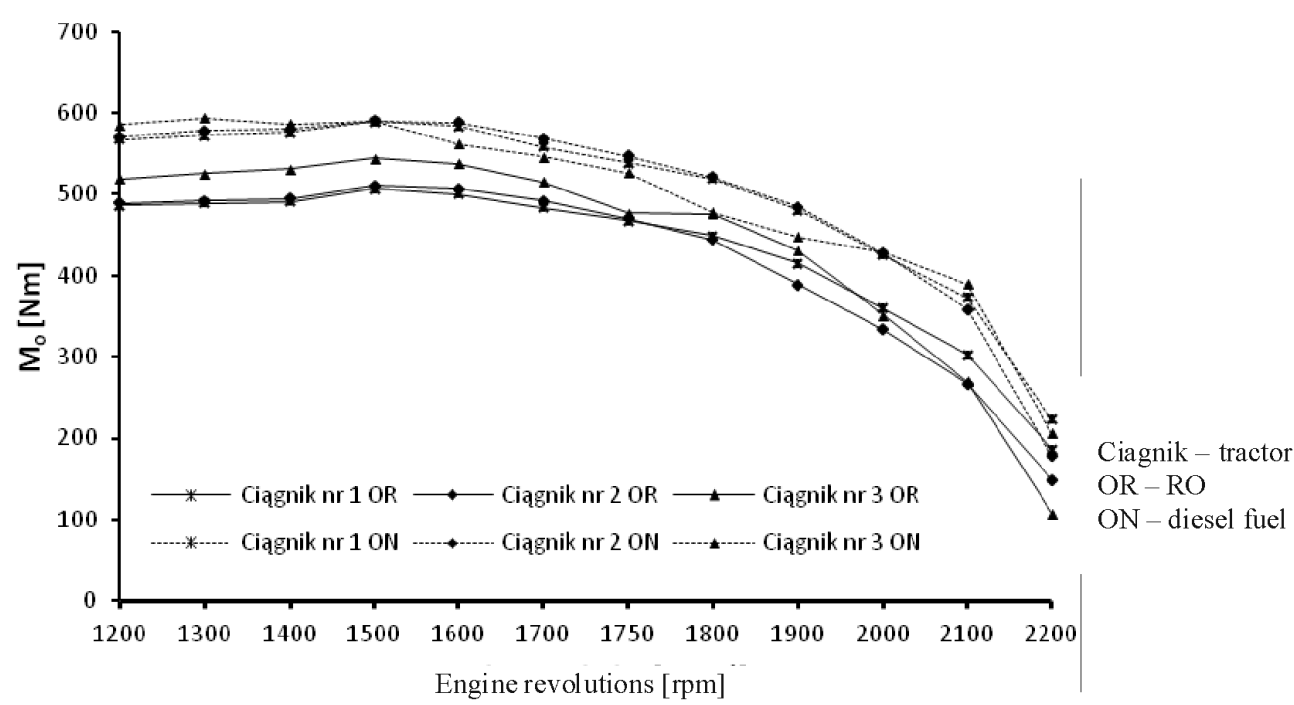

Fig. 1. Torque characteristics in the function of engine revolutions

Rys. 1. Charakterystyka momentu obrotowego w funkcjiprędkości obrotowej silnika cyjnych, następnie olejem napędowym. Do badań wykorzystano letni olej napędowy (ON) o znormalizowanych parametrach (EN 590) i tłoczony na zimno olej rzepakowy (OR) o parametrach przedstawionych $\mathrm{w}$ tabeli 1 .

Zmierzono parametry: moment obrotowy $\left(\mathrm{M}_{\mathrm{o}}\right)$ i godzinowe zużycie paliw (G). Na podstawie uzyskanych wartości określono moc silnika (Ne) i jednostkowe zużycie paliwa $\left(\mathrm{g}_{\mathrm{e}}\right)$.

\section{Wyniki badań}

Podczas wykonywanych badań eksploatacyjnych nie zaobserwowano negatywnego oddziaływania oleju rzepakowego na poziom awaryjności ciągników. W tabeli 2 podano wartości mierzonych i wyliczonych parametrów badanych ciągników.

W okresie badań ciągniki przepracowały od 1374 do 1774 motogodzin, zużywając w tym czasie od $10235 \mathrm{dm}^{3}$ do $24218 \mathrm{dm}^{3}$ paliwa. Parametry energetyczne pracy ciągników 1 i 2 były porównywalne: $\mathrm{M}_{\text {o }}$ około $510 \mathrm{~N} \cdot \mathrm{m}$ zasilone OR i 590 zasilone ON. $M_{0}$ ciągnika $n r 3$ oraz jego moc były wyższe względem pozostałych badanych obiektów. $\mathrm{M}_{\mathrm{o}}$ wynosił $544 \mathrm{~N} \cdot \mathrm{m}$ przy zasilaniu OR i 591 przy zasilaniu ON, oraz moc odpowiednio: 91,7 kW i $98,3 \mathrm{~kW}$. Podobnie 
revolutions consumed ca. $24.3 \pm 0.3 \mathrm{~kg} \cdot \mathrm{h}^{-1}$, tractor No 3 over $1.5 \mathrm{~kg} \cdot \mathrm{h}^{-1}$ more. Based on unitary fuel consumption, it is safe to say that fuel consumption for generating the power was comparable and amounted ca. $280 \mathrm{~g} \cdot \mathrm{kWh}^{-1}$ for all tested cases at rated engine speeds, however ge of tractor No 3 was $260 \mathrm{~g} \cdot \mathrm{kWh}^{-1}$ and was by $20 \mathrm{~g} \cdot \mathrm{kWh}^{-1}$ higher than the other two cases.

The below drawing presents torque distribution for three tested tractors supplied with rape oil, and then with diesel fuel.

Based on gathered examination results, it is found that in all three cases, application of rape oil affected the reduction of torque, within the whole range of engine revolutions. Plat oil is a substance of similar physical properties comparing to diesel fuel, however of significantly different chemical constitution. It mostly consists of triacylglycerols, particles of molar mass over three times higher that particles of diesel fuel, moreover it includes from 1-14\% of oxygen, that affects fuel combustion. At the diffusion stage of rape oil combustion, its heat generation dynamics is lower comparing to diesel fuel, leading to lower pressure imposed on cylinders [16-18]. Observed higher torque in Tractor No 3 was caused by increased amount of fuel (Fig. 1). Mo of engine supplied with rape oil comparing to other tractors was higher, however Mo of this tractor supplied with diesel fuel was lower. Drop of torque was also observed at 1750-1800 rpm only in tractor No 3.

Regardless of the applied fuel, $G$ of the tested tractors was comparable at engine revolutions $1700 \mathrm{rpm}$. Within the scope of rotational speed 1600-1900 rpm, total fuel consumption was constant and amounted within $24-26 \mathrm{~kg} \cdot \mathrm{h}^{-1}$. The below figure presents characteristics of unitary fuel consumption and power (Fig. 3).

Within all tested cases, maximum power of engines was obtained at $1700 \mathrm{rpm}$. Application of rape oil affects the growth of unitary fuel consumption by $20-40$ $\mathrm{g} \cdot \mathrm{kWh}^{-1}$. In the tested tractors, the consequence was the drop of power which fact is especially important in case of setting up tractor units. Engine power can be increased by increasing the fuel dose, as in case of tractor No 3, but this will affect the fuel consumption.

Operational tests of three independently operating agricultural tractors było przy pomiarze godzinowego zużycia paliwa: ciągniki nr 1 i 2 przy nominalnych obrotach silnika zużywały około $24,3 \pm 0,3 \mathrm{~kg} \cdot \mathrm{h}^{-1}$, ciągnik nr 3 o ponad $1,5 \mathrm{~kg} \cdot \mathrm{h}^{-1}$ więcej. $\mathrm{Na}$ podstawie jednostkowego zużycia paliwa można stwierdzić, że zużycie paliwa do generowanej mocy było porównywalne i wynosiło około $280 \mathrm{~g} \cdot \mathrm{kWh}^{-1}$ dla wszystkich badanych ciągników przy nominalnych obrotach silnika, natomiast ge ciągnika nr 3 wynosiło $260 \mathrm{~g} \cdot \mathrm{kWh}^{-1}$ i było o $20 \mathrm{~g} \cdot \mathrm{kWh}^{-1}$ wyższe niż dla dwóch pozostałych silników.

Na rysunku 1 przedstawiono rozkład momentu obrotowego trzech badanych ciągników zasilanych olejem rzepakowym, a następnie napędowym.

Na podstawie zebranych wyników badań można stwierdzić, że dla wszystkich trzech ciągników stosowanie oleju rzepakowego wpłynęło na obniżenie momentu obrotowego, równo w całym mierzonym zakresie obrotowym silnika. Olej roślinny jest substancją o podobnych właściwościach fizycznych do oleju napędowego, natomiast innej budowy chemicznej. Składa się głównie z triacylogiceroli, cząstek o masie molowej ponad trzykrotnie większej niż cząstki oleju napędowego, ponadto zawiera od 11-14\% tlenu, który ma wpływ na spalanie paliwa. W dyfuzyjnej fazie spalani oleju rzepakowego dynamika wywiązywania się ciepła jest mniejsza niż podczas spalania ON, czego następstwem jest mniejsze ciśnienie indykowane w cylindrach [16-18]. Zaobserwowano wyższy moment obrotowy w ciągniku nr 3, który był spowodowany zwiększoną dawką paliwa (rys. 1). $\mathrm{M}_{\mathrm{o}}$ silnika zasilanego olejem rzepakowym w porównaniu do innych ciągników było wyższe, natomiast Mo tego ciągnika zasilanego olejem napędowym było niższe. Zaobserwowano również spadek $M_{0}$ przy prędkości obrotowej 1750-1800 $\mathrm{min}^{-1}$ tylko w ciągniku nr 3.

Niezależnie od rodzaju zastosowanego paliwa, godzinowe zużycie paliwa badanych ciągników (rys. 2) było porównywalne przy prędkości obrotowej silnika $1700 \mathrm{~min}^{-1}$.

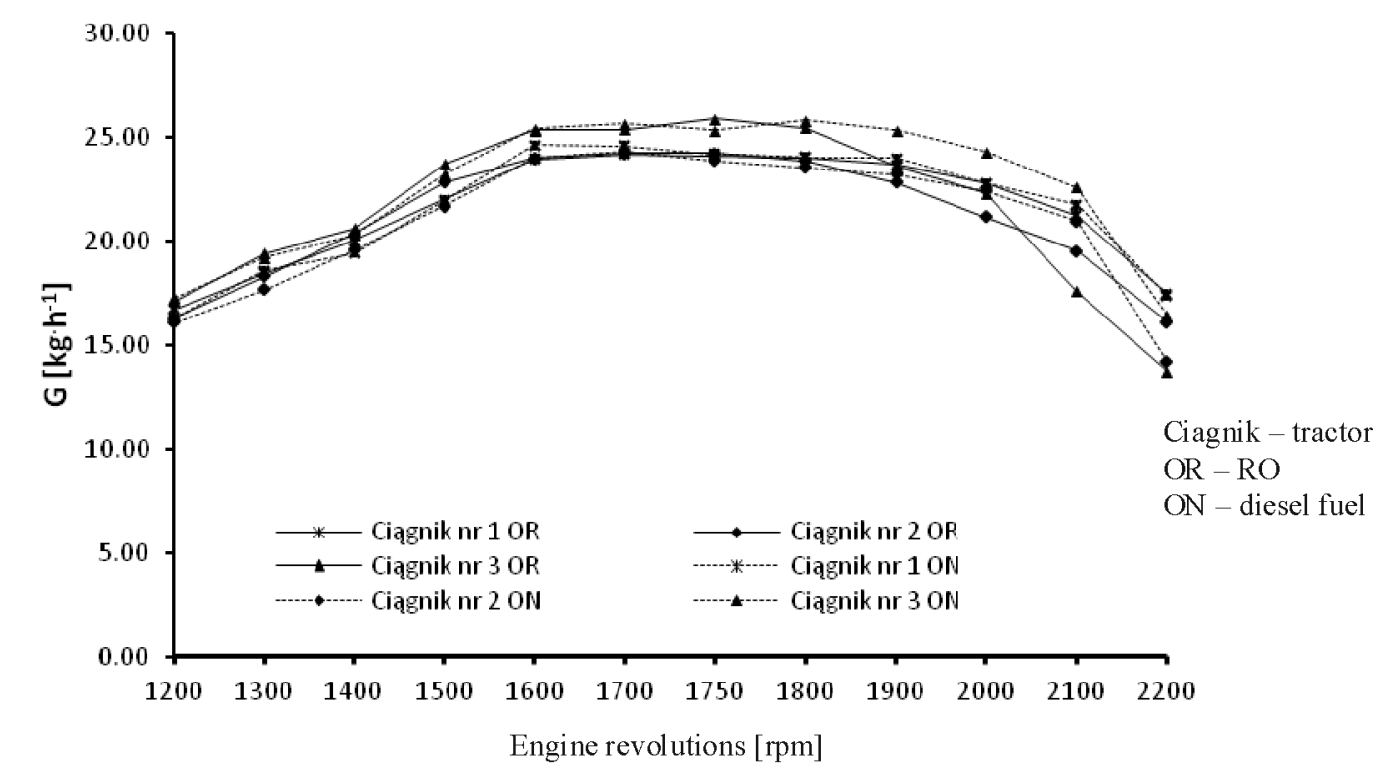

Fig. 2. Total fuel consumption characteristics in the function of engine revolutions Rys. 2. Charakterystyka godzinowego zużycia paliwa w funkcji prędkości obrotowej silnika 


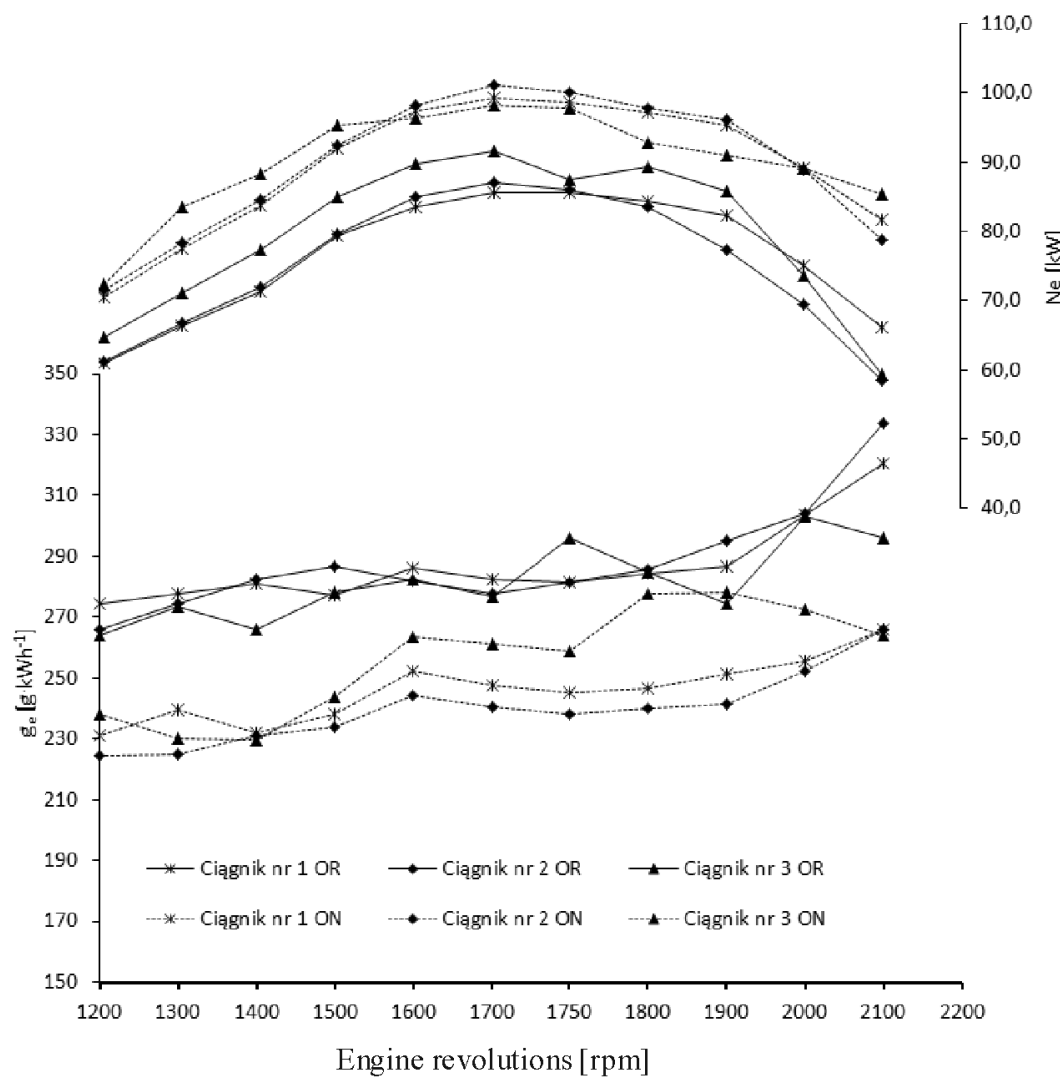

Fig. 3. Power and unitary fuel consumption characteristics in the function of engine revolutions Rys.3. Charakterystyka mocy i jednostkowego zużycia paliwa w funkcji prędkości obrotowej silnika

confirmed correct operation of a single-tank system supplying the engines. Rathbauer at al. [19] obtained similar research result performing its operational research on 38 vehicles with single-tank and double-tank system supplying the engines by rapeseed oil. Results of the tractor JD 6830 tests, compete with results of beginning of this study [20], shows that there aren't negative impact of rapeseed oil on tractor in longer exploitation.

\section{Conclusions}

- Based on the performed examinations, it was found that diesel engine 6068HL481, driving agricultural tractors JD 6830 , with single-tank fuel system for rape oil operates correctly when using rape oil that is in conformity with the standard DIN 51605.

- Differences in chemical constitution between rape oil and diesel fuel affect the increase of unitary fuel consumption by about $11 \%$. Main reason for that is share of oxygen in rape oil, that does not generate heat during fuel combustion.

- Power of the tested prototype of vehicles was comparable for each type of fuel they were supplied with and amounted in average $88 \mathrm{~kW}$ for rape oil and $98 \mathrm{~kW}$ for diesel fuel. This proves the correct operation, developed by John Deere single-tank system to power the tractor only rapeseed oil.
W zakresie prędkości obrotowej 1600 $1900 \mathrm{~min}^{-1}$ godzinowego zużycie paliwa wnosiło w granicach $24-26 \mathrm{~kg} \cdot \mathrm{h}^{-1}$. Na rysunku 3 przedstawiono charakterystyki jednostkowego zużycia paliwa i mocy.

We wszystkich badanych ciągnikach maksymalną moc silników uzyskano przy $1700 \mathrm{~min}^{-1}$. Stosowanie oleju rzepakowego wpływa na wzrost o $20-40 \mathrm{~g} \cdot \mathrm{kWh}^{-1}$ jednostkowego zużycia paliwa. W badanych ciągnikach konsekwencją tego jest spadek mocy ciągnika, co jest niezwykle ważne w zestawianiu agregatów ciągnikowych. Można zwiększyć moc silnika przez zwiększenia dawki paliwa, tak jak dla ciągnika nr 3 , jednak godzinowe zużycie paliwa wzrośnie, co $\mathrm{w}$ praktyce oznacza większe zużycie paliwa.

Badania eksploatacyjne trzech niezależnie działających ciągników rolniczych potwierdziły poprawne działanie jednozbiornikowego systemu zasilania silników. Podobny rezultat badań uzyskał Rathbauer wraz z zespołem [19], prowadząc badania eksploatacyjne 38 pojazdów z jednozbiornikowymi i dwuzbiornikowymi systemami paliwa, zasilanymi olejem rzepakowym. Wyniki badań ciągnika JD 6830, w porównaniu do parametrów energetycznych określonych na początku ich eksploatacji [20], były porównywalne, co świadczyło o braku negatywnego oddziaływania oleju rzepakowego w dłuższym okresie eksploatacji tych ciągników.

\section{Wnioski}

- Na podstawie wykonanych badań stwierdzono, że silniki ZS model 6068HL481, napędzające ciągniki rolnicze JD 6830, z jednozbiornikową instalacją paliwa do oleju rzepakowego pracuja poprawnie przy zasilaniu olejem rzepakowym o jakości zgodnej z normą DIN 51605.

- Różnice pomiędzy budową chemiczną oleju rzepakowego a napędowego wpływają na wzrost jednostkowego zużycia paliwa o około $11 \%$ we wszystkich badanych przypadkach. Główną przyczyną tego jest udział tlenu w oleju rzepakowym, który w wyniku spalania paliw nie wydziela ciepła.

- Moc badanych prototypowych ciągników była porównywalna dla każdego z rodzaju paliwa jakim był zasilony; wynosiła średnio $88 \mathrm{~kW}$ dla zasilanych olejem rzepakowym i $98 \mathrm{~kW}$ dla zasilanych tradycyjnym olejem napędowym. Świadczy to o poprawnie działającej, opracowanej przez John Deere, instalacji jednozbiornikowej do zasilania ciągników wyłącznie olejem rzepakowym. 


\section{Bibliography/Literatura}

[1] Dharma Y.C., Singh B., Upadhyay S.N.: Advancements in development and characterization of biodiesel: A review. Fuel 2008;87:2355-2373.

[2] Senthil Kumar M., Ramesh A., Nagalingam B.: An experimental comparison of methods to use methanol and Jatropha oil in a compression ignition engine. Biomass Bioenergy 2003;25:309-318.

[3] Wyatt V.T., Hess M.A., Dunn R.O., Foglia T.A., Haas M.J., Marmer W.N.: Fuel properties and nitrogen oxide emission level of biodiesel produced from animal fats. JAOCS 2005;82:585-591.

[4] Predojewić Z.J.: The production of biodiesel from waste frying oils: A comparison of different purification steps. Fuel 2008;87:3522-3528.

[5] Wang Y., Ou S., Liu P., Zhang Z.: Preperation of biodiesel from wast cooking oil via two-steps catalyzed process. Energy Conversation and Management 2007;48:184-188.

[6] Lapuerta M., Herreros J.M., Lyons L.L., Garcia-Contreras R., Briceňo Y.: Effect of the alcohol type used in the production of waste cooking oil biodiesel on diesel performance and emissions. Fuel 2008; 87:3161-3168.

[7] Frąckowiak P.: Testing of esterification process of rape oil for tractor fuel in the prototype production plats of $400 \mathrm{dm} 3$ output. Journal of Research and Replications in Agricultural Engineering 2002; 47:67-73.

[8] Grzybek A.:Technologie transestryfikacji oleju rzepakowego. W: Biopaliwa gliceryny, pasze z rzepaku. Pr. zbior. Pod red. W. Podkówki. Bydgoszcz. Wydaw. Uczelni ATR, 2004, s. 70-83.

[9] Thompson J.C., He B.B.: Characterization of crude glycerol from biodiesel production from multiple feedstocks. Applied Engineering in Agriculture Vol. 2(22), 2006, s. 261-265.

[10] Golimowski W., Golimowska R.: Ocena wartości opałowej fazy glicerynowej oraz jej mieszanin z biomasą. Problemy Inżynierii Rolniczej nr 3(69), 2010, s. 103-108.

[11] Golimowski W., Kliber A.: Influence of raw glycerol phase from esterification process of waste cooking oil on the increase of plant organic matter. Problemy Inżynierii Rolniczej nr 2(76), 2012, s. 55-62.
[12] Golimowski W., Graczyk A.:The influence of waste fats esterification process parameters in agricultural biofuel production facilities. Environment Protection Engineering 4/2011, s. 5562

[13] Golimowski W., Golimowska R., Kliber A.:Temperature effect on kinematics viscosity of animal fats, vegetable oils and its transesterification product. Journal of Research and Applications in Agricultural Engineering, vol. 56(1), 2011, s. 50-55.

[14] Hemmerlein N., Korte V., Richter H., Schroeder G.:Performance, exhaust emissions and durability of modern diesel engines running on rapeseed oil. SAE Technical Papers Series 910848, 1991.

[15] Senthil Kumar M., Kerihuel A., Bellettre J., Tazerout M.: Experimental investigations on the use of preheated animal fat as fuel in a compression ignition engine. Renewable Energy 30 (2005), p. 1443-1456.

[16] Buyukkaya E.: Effects of biodiesel on a DI diesel engine performance, emission and combustion characteristics. Fuel 2010;89:3099-3105.

[17] Sahoo P.F., Das L.M.: Combustion analysis of jatropha, karanja and polanga based biodiesel as fuel in a diesel engine. Fuel 2009; 88: 994-999.

[18] Devan P.K., Mahalakshmi N.V.: Study of the performance, emission and combustion caharacteristics of a diesel engine using poon oil-based fuels. Fuel Processing Technology 2009; 90: 513-519.

[19] Rathbauer J., Krammer K., Kriechbaum T., Prankl H., Breinesberger J.: Rapsöl als Treibstoffalternative für die Landwirtschaft BMLFUW-LE.1.3.2/0037-II/1/2006. Forschungsprojekt No. 1337.

[20] Pasyniuk P., Golimowski W.: Work indicators test for prototype John Deere 6830 agricultural tractor fueled with pure vegetable oil. Technical Sciences vol. 14(1),2011, s. 109-117.

Piotr Pasyniuk, DEng. - doctor doctor in the Institute of Technology and Life Sciences in Falenty, Department of Renewable Energy Resources.

Dr inż. Piotr Pasyniuk - adiunkt w Instytucie Technologiczno-Przyrodniczym $w$ Falentach, oddziat $w$ Warszawie, kierownik Laboratorium Badawczego e-mail:p.pasyniuk@itep.edu.pl

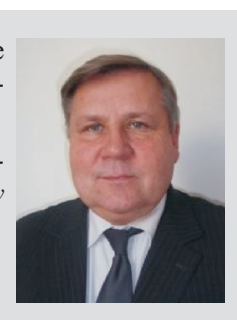

Renata Golimowska, DEng. - doctor in the Institute of Technology and Life Sciences in Falenty, Department of Renewable Energy Resources.

Dr inż. Renata Golimowska-adiunkt w Instytucie Technologiczno-Przyrodniczym w Falentach, oddział w Poznaniu, Zakład Odnawialnych Źródet Energii.

e-mail: r.golimowska@itep.edu.pl of Technology and Life Sciences in Falenty, Department of Renewable Energy Resources.

Dr inż. Wojciech Golimowski - adiunkt w Instytucie Technologiczno-Przyrodniczym w Falentach, oddział w Poznaniu, Zakład Odnawialnych Źródet Energii.

e-mail: w.golimowski@itep.edu.pl

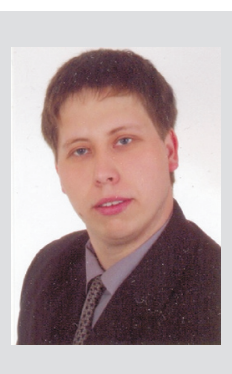

